\title{
Heat transfer and entropy generation analysis of internal flow of nanorefrigerant with slip condition at wall
}

\author{
S. Mohamadi ${ }^{1}$, M.H. Yazdi ${ }^{1}{ }^{*}$, E. Solomin ${ }^{1}$, A. Fudholi ${ }^{2}$, K. Sopian ${ }^{2}$ and P.L. Chong ${ }^{3}$
}

${ }^{1}$ Department of Electric Power Generation Stations, Network and Supply Systems, Institute of Engineering and Technology, South Ural State University, 76, Lenin Avenue, Chelyabinsk, 454080, Russian Federation

2 Solar Energy Research Institute, University Kebangsaan Malaysia, 43600, Bangi, Selangor, Malaysia

3 School of Computing, Engineering and Digital Technologies, Teesside University, Middlesbrough, TS1 3BX. United Kingdom

*Email:mohammadhossein.yazdi@gmail.com.

\begin{abstract}
Heat transfer enhancement has always been the main purpose in designing the heat exchangers in various industrial applications. In addition, nanofluids have shown potential as industrial cooling fluids due to the enhanced heat transfer characteristics particularly in heat exchanger applications. Whilst enhancing heat transfer using nanofluids, there is a trade-off of causing higher irreversibility and pressure drop. Therefore, in order to have a better view of thermal performances, it is necessary to consider other aspects of the thermal system in addition to heat transfer factors such as pressure drop and entropy generation. In the present study, the heat transfer characteristics and entropy generation analysis of a laminar nanofluid flow in a 3 $\mathrm{mm}$ horizontal circular tube subjected to a uniform heat flux and slip boundary condition is evaluated numerically using ANSYS Fluent software. Two types of nanofluids that are obtained
\end{abstract}


from dispersing of $\mathrm{Al}_{2} \mathrm{O}_{3}$ and $\mathrm{SiO}_{2}$ nanoparticles in pure $\mathrm{HFE7000}$ are considered with particle volumetric concentrations of $0,1,4$ and 6\% and Reynolds numbers of 400, 800, 1200 and 1600. Results indicate that mean pressure drop reduces about $25 \%$ by using the slip boundary condition at the wall. In addition, while using a slipping wall pipe with slip length of $100 \mu \mathrm{m}$ and $6 \%$ volume concentration of $\mathrm{Al}_{2} \mathrm{O}_{3}$ dispersed in HFE7000, total entropy generation decreases about $20 \%$ in comparison to pure HFE7000 flowing in a no-slip pipe.

Key words: Nanofluid; entropy generation analysis; slip boundary condition; heat transfer; 


\section{Nomenclature}

$\boldsymbol{A}$ area, $\mathbf{m}^{2}$

$\boldsymbol{C}_{\boldsymbol{p}}$ specific heat J/kg K

$\boldsymbol{C}_{\boldsymbol{f}}$ skin friction coefficient

$\boldsymbol{D}$ diameter, $\mathrm{m}$

\section{$f$ friction factor}

$\boldsymbol{h}$ heat transfer coefficient $\mathrm{W} /\left(\mathrm{m}^{2} \mathrm{~K}\right)$

$\boldsymbol{K}$ thermal conductivity $\mathrm{W} / \mathrm{mK}$

$\boldsymbol{L}$ length, m

$\boldsymbol{L}_{\boldsymbol{s}} \boldsymbol{s}$ lip length, $\mathrm{m}$

$\mathrm{Nu}$ Nusselt Number

$\boldsymbol{R}$ radius of tube, $\mathrm{m}$

$\boldsymbol{P}$ pressure, $\mathrm{Pa}$

$\ddot{\boldsymbol{q}}$ heat flux $\mathrm{W} / \mathrm{m}^{2}$

$\boldsymbol{R} \boldsymbol{e}$ Reynolds number

$S$ entropy (W/K)

$\boldsymbol{T}$ temperature, $\mathrm{K}$

$\boldsymbol{u}$ velocity in axial direction, $\mathrm{m} / \mathrm{s}$

$\dot{W}$ workrate, $\mathrm{W}$

Abbreviations

$\boldsymbol{G W P}$ global warming potential

$\boldsymbol{H F E}$ hydro fluoro ether

$\boldsymbol{O D P}$ ozone depletion potential
Subscript

ave average

$\boldsymbol{b} \boldsymbol{f}$ basefluid

$f$ fluid

$\boldsymbol{f r}$ frictional

gen generation

in inlet

$\boldsymbol{l}$ length, $\mathrm{m}$

$\boldsymbol{m}$ mean

$\boldsymbol{n f}$ nanofluid

out outlet

$\boldsymbol{s}$ nanoparticle(solid)

th thermal

tot total

$\boldsymbol{w}$ wall

Greek Symbols

$\boldsymbol{\rho}$ density $\mathrm{kg} / \mathrm{m}^{3}$

$\boldsymbol{\eta}$ first law efficiency

$\boldsymbol{\varepsilon}$ second law efficiency

$\boldsymbol{\mu}$ dynamic viscosity, $\mathrm{kg} / \mathrm{m} \mathrm{s}$

$\varnothing$ volume concentration of nanoparticle 


\section{INTRODUCTION}

Heat transfer in different applications can be increased by some factors. One of them is geometric parameters such as channel shape and pipe diameter. For instance, study results of Sarma et al.[1] showed an increased surface area to volume ratio significantly affects the flow dynamics in such miniaturized systems. Another factor is fluid conditions at the inlet such as pressure, temperature and velocity. Heat source conditions can be another factor. Physical and thermo physical properties of fluid or nanofluid such as viscosity, thermal conductivity, density, thermal capacity, volume fraction concentration, nanoparticles size are other factors that could be considered [2]. In industrial application some factors are constant and others can change. For example while pumping power and channel geometry are unchangeable, fluid properties and boundary conditions are problem variables. One of the methods for changing properties of fluid is to add nanoparticles to the base fluid. Nano-sized particles that are dispersed in conventional fluids can improve the performance of fluids in heat transfer enhancement. This type of fluids are called nanofluids and are used widely in various applications such as heat exchangers, thermal energy storage and industrial cooling systems [3].Thermal conductivity can be increased by this method. Most of commercially nanoparticles are in type of dry powders. These nanoparticles are in different geometries such as plate, branch, pipe, spherical and bar type. Main difference in using micro particles and nano particles is the ratio of area to the volume that is much larger for nanoparticles. Increasing this ratio enhances the reaction of particles for example oxidation reaction. Therefore, usual nanoparticles have oxidation combination such as $\mathrm{Al}_{2} \mathrm{O}_{3}$ and $\mathrm{SiO}_{2}$. are significant constituent in offshore interventions.

For most of thermal systems increasing heat transfer is accompanied with undesirable significant pressure drop and entropy generation. Therefore, in order to have a better view of thermal performance, we should consider other aspects of a thermal system in addition to heat transfer parameters. Entropy generation analysis is one of the most powerful techniques to investigate the performance of thermal systems. There is an influential role of different 
performance index parameters viz., the geometric parameters, material properties, flow conditions on the irreversibility generation rate of the system [4]. Many researchers have studied entropy generation of thermal systems to determine the optimum operating conditions. Minimizing of global irreversibility of the system is the main subject of related investigations. The investigation results of Gaikwad et al. [5] unveil optimum value of geometrical and thermo-physical parameters leads to a minimum entropy generation in the system. The effect of adding nanoparticles to the base fluid is not considered in their study. Investigation results for the effects of $\mathrm{Al}_{2} \mathrm{O}_{3}$ nanoparticle volume concentration on entropy generation of water- $\mathrm{Al}_{2} \mathrm{O}_{3}$ nanofluid flow through a circular pipe under constant wall heat flux boundary condition in laminar and turbulent regimes by Moghadami et al. [6] show that an increase in volume concentration of nanoparticle causes a decrease in thermal entropy generation and as a results, an increase in the friction entropy generation. In the turbulent flow both of the friction and thermal entropy generation terms are at the same order of magnitude, while in the laminar regime the effect of the thermal entropy generation strongly outweighs than that of friction entropy generation. Another investigation is about the effects of geometry and flow regimes on entropy generation studied by Singh et al [7]. They investigated the heat transfer and entropy generation of $\mathrm{Al}_{2} \mathrm{O}_{3}$ dispersed in water in turbulent flow regime. Their results show an optimum diameter in entropy generation for turbulent flows inside the channel. The results of numerical analysis on the effect of using $\mathrm{Al}_{2} \mathrm{O}_{3}$-water with different volume concentration on hydrodynamic performance and thermal characteristics studied by Shalchi Tabrizi et al. [8] indicating that using nanofluids as a cooling fluids will lead to a significantincrease in heat transfer. In addition, heat transfer enhances with increase in volume concentration, however using of nanofluids need a more powerful pumping source. Finally, they concluded that the increase in volume concentration and Reynolds number and decrease in nanoparticle diameter tend to decrease the entropy generation. Also change in fluid temperature and temperature gradient across the fluid and the walls of the channel alters the heat transfer rate, leading to the entropy generation in the system, investigated by Gaikwad et al [9]. As indicated, the increase in heat transfer is accompanied with undesirable significant 
pressure drop and entropy generation in most cases. Therefore, if we could compensate these variables, we would have achieved a better thermal performance. One of the techniques to decrease pressure drop is to use surfaces with slip boundary condition at the walls. Superhydrophobic surfaces can be noticed as a practical model of a slipping surface. This kind of surfaces contain micro or nanoscale hydrophobic features which can support a shear-free air-water interface between peaks in the surface topology [10] . The slip-length based on the Navier slip condition at the wall is independent of the precise flow over the surface and can be used to describe the slip boundary condition[11] using of these boundary conditions decrease the drag and friction in both laminar and turbulent flow regimes [12]. These slippage surfaces could be produced from some polishing methods with organic materials such as paraffinic hydrocarbons and some inorganic materials such as $\mathrm{ZnO}$ and $\mathrm{TiO}_{2}$. Micro sized roughness of these surfaces make fluids to slip on the surface and this mechanism reduces the fluid-solid contact and friction. Besides, the results of the two-dimensional squeezing nanofluid flow under the effects of a uniform transverse magnetic field and slip boundary conditions, have been studied by Sobamovo et al. [13] illustrating that in slip condition, fluid velocity increases with the increase of magnetic field while in the case of no-slip condition fluid velocity decreases with enhancement of magnetic field. In another study investigated by Yazdi et al., the slip velocity effect shows a reduction in wall friction through flow boundary layer [14]. According to the results of other investigation done by Somasekhar et al. [15], adding nanoparticles to the water could significantly increase the heat transfer characteristics. The nanoparticle distribution analysis investigated by Malvandi et al [16] also indicate that nanoparticles migrate from heated wall toward the axis of microchannel and have non-uniform distribution. Investigation results of the transient and steady state flow regimes of slip flow condition studied by Chen et al. [17] indicate the pressure driven flow and shear flow are in opposite direction, the stationary liquid may be generated on the moving wall. This phenomenon is important to prevent liquid leakage during wafer scanning and the corresponding parameters are optimized in order to improve advanced immersion lithography. The results of another investigation done by Xie et al. [18] have indicated that wall slip and inertial force do not have 
significant influence on load capacity and friction force. Inertial force slightly increases the pressure and the load capacity by $1.2 \%$ and $4.8 \%$ respectively, while the wall slip decreases pressure and load capacity by $15.98 \%, 2.33 \%$, respectively. Inertial force and wall slip decrease friction by about $15.98 \%, 2.33 \%$, respectively. An increase in volume concentration and slip velocity coefficient tend to enhance the heat transfer rate studied by Rahmati et al. [19]. Their results show that with the increase in slip velocity coefficient would be a better chance of decreasing the temperature gradient at the wall. In their study the entropy generation analysis is not considered. Thus, it could be an interesting research to evaluate the second law of thermodynamic in the presence of slip reaching to an appropriate design of nanofluid flow and heat transfer. Numerically analysis of the flow and heat transfer characteristics of low pressure gas in slip flow regime is the subject of another investigation in this field by Xie, et al.[20]. Moreover, entropy generation analysis results by Karimzadehkhouei, et al.[21] show a significant increase in entropy generation while adding $\mathrm{Al}_{2} \mathrm{O}_{3}$ and $\mathrm{TiO}_{2}$ to the base fluid. The effect of slip boundary condition is not considered in their study as well.

Researchers have found that a group of hydrofluoroethers can be used as substitute of HFC, HCFC, CFC gases due to their similar properties such as low conduction coefficient, low surface tension, high volatility and low flammability. In addition, high ozone deflection effect of CFC and HCFC gases made HFEs as third generation of refrigerant gases. Shorter life time and lower global warming potential (GWP) are two other reasons for using HFEs. The investigation on HFEs as a base fluid in nanofluid flow and heat transfer is a motivating research and it is noted that HFE7000 would be the base fluid considered in this study with chemical formula of $\mathrm{C}_{3} \mathrm{~F}_{7} \mathrm{OCH}_{3}$. There have been many theoretical and numerical models developed specifically for entropy generation analysis of nanofluids inside of the pipe. However, to the best of our knowledge, no investigation has been made yet to analyze the entropy generation analysis of the slip nanofluid flow and heat transfer with HFE7000 base fluid with uniform heat flux condition. Therefore, the objective of this study is to increase the heat transfer enhancement and to reduce exergy losses of nanorefrigerant flow inside the tube in the presence of slip boundary condition. 


\section{MODELING AND ANALYSIS}

In this study numerical solution is accomplished using finite volume method software ANSYS 19.0. Figure 1 shows schematic of analysis model. After two-dimensional modelling and meshing a $3 \mathrm{~mm}$ diameter pipe with length of $500 \mathrm{~mm}$, solution is run only for the top half of model because of symmetrical assumptions. Fluid enters the tube at the pressure of $1 \mathrm{bar}$ and temperature of $283 \mathrm{~K}$. Constant heat flux of $1000 \mathrm{~W} / \mathrm{m}^{2}$ is subjected to the top wall as the source of heat. Inlet velocity is for different Reynolds numbers of 400, 800, 1200 and 1600. Considered slip length in our study assuming superhydrophobic surfaces is between 50 to $200 \mu \mathrm{m}$

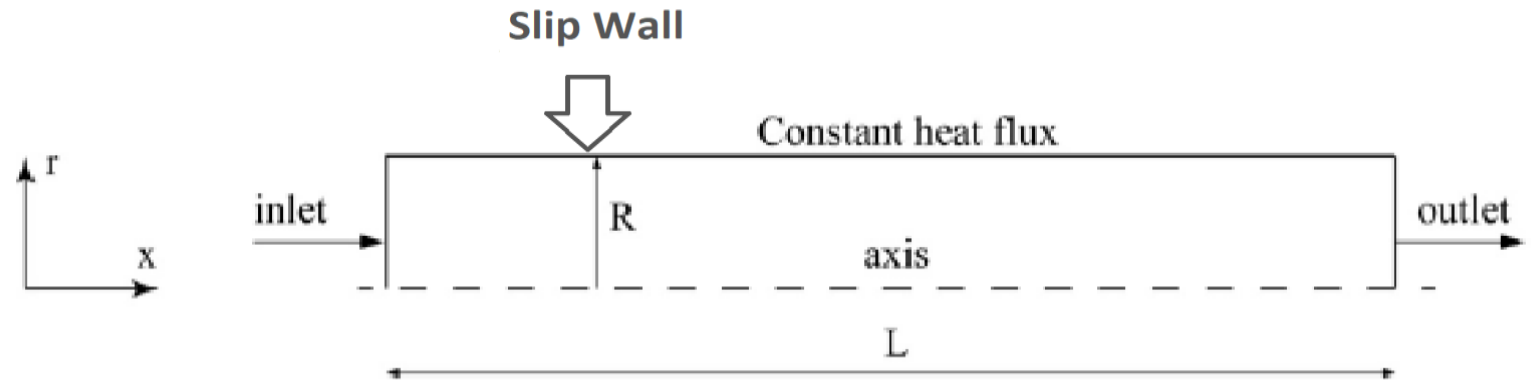

Figure 1 schematic of present internal flow model

At the first step of the modeling, pure HFE7000 is used as fluid and there is no-slip condition at the wall. Next, the computation is carried out with slip boundary condition at the wall using $\mathrm{Al}_{2} \mathrm{O}_{3}$ and $\mathrm{SiO}_{2}$ nanoparticles to the base fluid with a volume fraction of 1,4 and $6 \%$. Nanofluid is assumed as a single phase homogenous fluid low and incompressible. The fundamental continuity, momentum and energy equations are shown as:

Continuity equation

$$
\nabla \cdot\left(\rho_{n f} V\right)=0
$$

Momentum equation

$$
\nabla \cdot\left(\rho_{n f} V V\right)=-\nabla P+\nabla \cdot\left(\mu_{n f} \nabla V\right)
$$

Energy equation

$$
\nabla \cdot\left(\rho_{n f} V C_{p} V\right)=\nabla \cdot\left(K_{n f} \nabla T\right)
$$


Table 1 illustrates the thermodynamic properties of fluids and nanoparticles that are used in this paper.

As observed, the case of $\mathrm{Al}_{2} \mathrm{O}_{3}$ indicate the highest density and specific heat compared to the water flow.

Table 1 Properties of water, HFE7000 and particles

\begin{tabular}{|l|l|l|l|l|l|}
\hline $\begin{array}{l}\text { Fluid/particle } \\
\text { Properties }\end{array}$ & $\begin{array}{l}\text { Density } \\
\mathrm{kg} / \mathrm{m}^{3}\end{array}$ & $\begin{array}{l}\text { Specific Heat } \\
\mathrm{J} /(\mathrm{kg} . \mathrm{K})\end{array}$ & $\begin{array}{l}\text { Thermal } \\
\text { Conductivity } \\
\mathrm{W} /(\mathrm{m} . \mathrm{K})\end{array}$ & $\begin{array}{l}\text { Viscosity } \\
\mathrm{kg} /(\mathrm{m} . \mathrm{s})\end{array}$ & Reference \\
\hline Water & 998.2 & 4182 & 0.6 & 0.001003 & {$[22]$} \\
\hline $\mathrm{HFE7000}$ & 1446.1 & 1204.6 & 0.079 & 0.00058 & {$[23]$} \\
\hline $\mathrm{Al}_{2} \mathrm{O}_{3}$ & 3970 & 765 & 40 & - & {$[24]$} \\
\hline $\mathrm{SiO}_{2}$ & 2200 & 703 & 1.2 & - & {$[25]$} \\
\hline
\end{tabular}

Density of nanofluid is defined as

$$
\rho_{n f}=\varnothing \rho_{s}+(1-\emptyset) \rho_{b f}
$$

where $\emptyset$ is volume concentration of nanoparticle, $\rho_{s}$ is nanoparticle density and $\rho_{b f}$ is density of base fluid. Dynamic viscosity can be calculated by Einstein's equation [28] as:

$$
\mu_{n f}=\mu_{b f}(1+2.5 \emptyset)
$$

where $\mu_{n f}$ is nanoparticle dynamic viscosity and $\mu_{b f}$ is dynamic viscosity of base fluid. Thermal conductivity is estimated by the following equation [29]:

$$
k_{n f}=k_{b f} \frac{\left[k_{s}+(n-1) k_{b f}+(n-1) \emptyset\left(k_{s}-k_{b f}\right)\right]}{\left[k_{s}+(n-1) k_{b f}-\emptyset\left(k_{s}-k_{b f}\right)\right]}
$$

where $n$ is the parameter for the shape of solid particle and is equal to 3 for the spherical ones. $k_{b f}$ and $k_{s}$ are the thermal conductivities of the base fluid and solid particles, respectively. Specific heat is obtained by following equation [30],

$$
C_{p, n f}=\frac{\left.\emptyset\left(\rho c_{p}\right)_{s}+(1-\emptyset)\left(\rho c_{p}\right)_{b f}\right)}{\left.\emptyset \rho_{s}+(1-\emptyset) \rho_{b f}\right)}
$$


where $c_{p, b f}$ and $c_{p, s}$ are the heat capacity of the base fluid and solid particles respectively. The inlet fluid velocity is also related to the following Reynolds number,

$$
\text { Velocity of nanofluid }(\mathrm{V})=\frac{\text { Reynolds number } * \mu_{n f}}{\rho_{n f} * D}
$$

At the first, the wall boundary condition is assumed as no slip condition and the wall shear stress would be in the case of no-slip without velocity slip at the wall. The next step of numerical analysis is related to the velocity slip boundary condition whereby a lower shear stress would be exerted at the wall. According to the Navier's model, the slip velocity at solid-liquid boundaries is linearly proportional to the velocity gradient at the surface. The velocity slip and velocity gradient at the wall are related to the slip length as follows [31],

$$
l_{s}=\frac{u_{s}}{d u / d y_{\mid w}}
$$

By means of the exerted shear stress and the velocity gradient at the wall, the slip length is applied in order to be applied at the numerical analysis. It is noted that the constant heat flux of $1000 \mathrm{~W} / \mathrm{m}^{2}$ is subjected to the upper wall and inlet developing length is assumed $500 \mathrm{~mm}$. Continuity, momentum and energy equations are solved by boundary conditions using ANSYS Fluent 19.0. Equations for calculating coefficients and heat transfer parameters are expressed below. Local heat transfer coefficient

$$
h(x)=\frac{q^{\prime \prime}}{T(x)_{w}-T(x)_{f, m}}
$$

Where $T(x)_{w}$ is the local temperature of the wall. This variable is equal to the largest value of calculated temperature for meshes at given $(x) . T(x)_{f, m}$ is also referred as the mean fluid temperature at $(x)$. Average Nusselt number is obtained by:

$$
N u_{a v e}=\frac{h_{a v e} D}{K}
$$

Where $\mathrm{D}$ and $\mathrm{K}$ are diameter of tube and thermal conductivity of pure fluid/nanofluids respectively. Average temperature is defined as:

$$
T_{\text {ave }}=\frac{T_{\text {in }}-T_{\text {out }}}{\ln \left(\frac{T_{\text {in }}}{T_{\text {out }}}\right)}
$$


Total entropy generation that consists of two parts: thermal and friction irreversibilities [32]

$$
S_{\text {tot }}=\frac{\left(q^{\prime \prime}\right)^{2} \pi D^{2} L}{N u k T_{\text {ave }}{ }^{2}}+\frac{32 \dot{m}^{3} f L}{\pi^{2} \rho^{2} T_{a v e} D^{5}}
$$

Where $\dot{m}$ is the mass flow rate and $\rho$ is the density of pure fluid/nanofluids. $f$ indicates friction factor:

$$
f=\frac{2 \cdot \Delta P \cdot D}{\rho \cdot V^{2} \cdot L}
$$

Where $\Delta P$ indicates pressure drop from inlet to outlet and $V$ is inlet fluid velocity. In this study, the Bejan number is defined as the ratio of heat transfer irreversibility to the total irreversibility due to heat transfer and fluid friction for the laminar nanofluid boundary layer flow. Mathematically, Bejan number is given as

$$
\text { Bejan number }=\frac{\text { Heat transfer irreversibility }}{\text { Entropy generation number }}
$$

\section{Meshing independency}

Meshing should be optimized in order to have acceptable precision and prevent not necessary calculation. In Table 2 entropy result for some different meshes is shown at Reynolds number of 800 .

Table 2 Meshing independency

\begin{tabular}{|l|l|l|l|}
\hline Row & Number of Meshing & Mean Fluid Temperature & \% Difference \\
\hline 1 & $2400 * 6$ & 284.78 & - \\
\hline 2 & $3600 * 10$ & 284.86 & 0.02 \\
\hline 3 & $4800 * 12$ & 284.85 & 0.003 \\
\hline 4 & $6000 * 14$ & 284.85 & 0.001 \\
\hline
\end{tabular}

Figure 2 shows the modelling of the mesh in this study. 


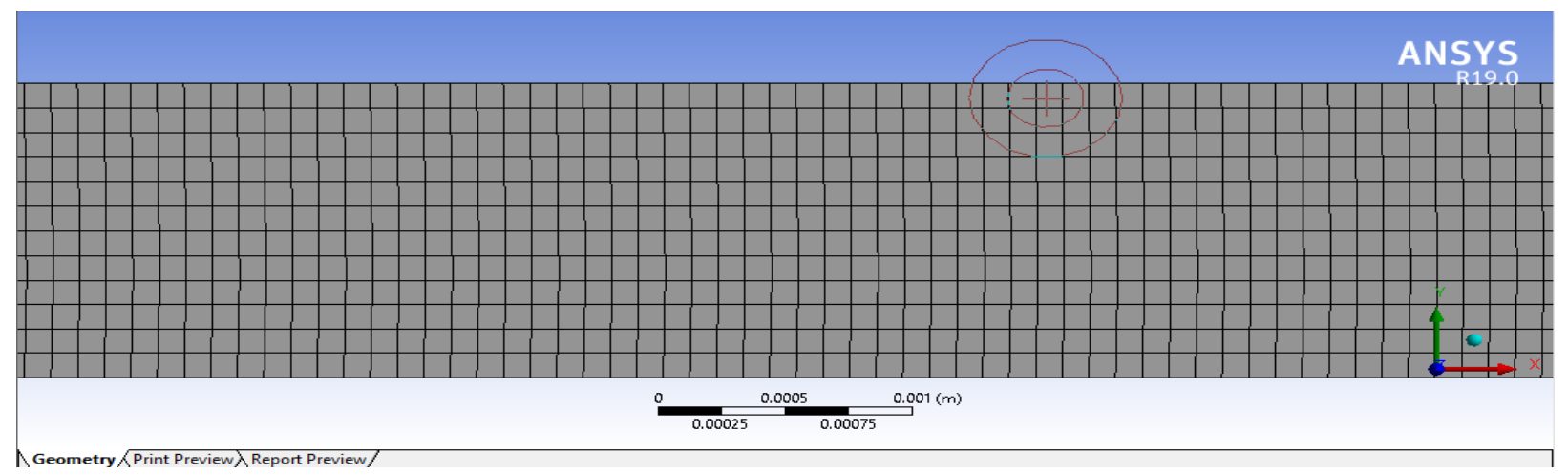

Figure 2 Meshed Model

Simple scheme is used for pressure-velocity coupling relation. In addition, second order scheme is chosen for the pressure, momentum and energy spatial discretization and Least Squares Cell Based for the gradient segment. Figure 3 shows the solution iterations in workbench of ANSYS 19.0.

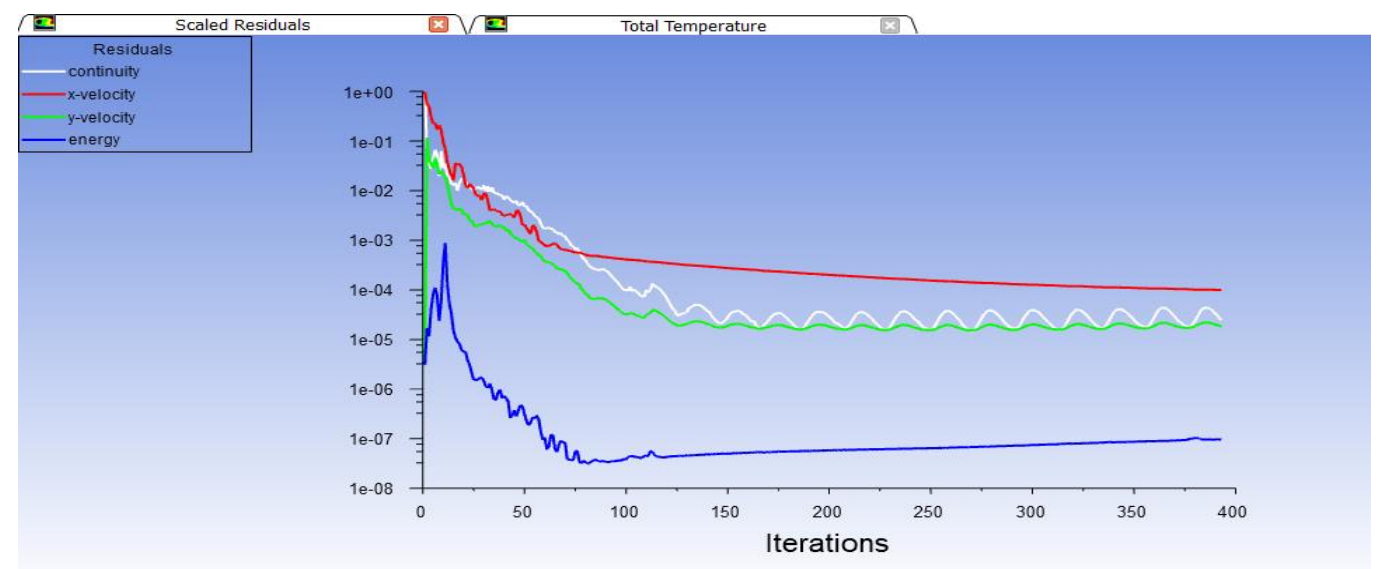

Figure 3 Convergence diagram

In order to validate the study, we compare the solution results for average heat transfer coefficient with a similar study. Results are obtained for a flow of HFE7000 with different volume concentration of $\mathrm{Al}_{2} \mathrm{O}_{3}$ nanoparticles, along a pipe with diameter of $4.75 \mathrm{~mm}$ and length of $1.2 \mathrm{~m}$ at the Reynolds number of 800 and a constant heat flux of $1000 \mathrm{w} / \mathrm{m}^{2}$ is subjected to the wall. As it is shown in Table 3, results have a good agreement. 
Table 3 Comparing average heat transfer coefficient results at Reynolds number of 800 in the present study with the study of Helvacy and Khan[33]

\begin{tabular}{|c|c|c|c|c|c|}
\hline \multicolumn{6}{|c|}{ Comparing average heat transfer coefficient results } \\
\hline & \multirow{2}{*}{$\begin{array}{c}\text { Reynolds } \\
\text { numbers }\end{array}$} & \multicolumn{4}{|c|}{$\begin{array}{ll} & \text { Fluid } \\
\end{array}$} \\
\hline & & HFE7000 & $\mathrm{HFE} 7000+1 \% \mathrm{Al}_{2} \mathrm{O}_{3}$ & $\mathrm{HFE} 7000+1 \% \mathrm{Al}_{2} \mathrm{O}_{3}$ & $\mathrm{HFE} 7000+1 \% \mathrm{Al}_{2} \mathrm{O}_{3}$ \\
\hline \multirow{4}{*}{$\begin{array}{l}\text { Present } \\
\text { study }\end{array}$} & 400 & $97 / 71$ & $100 / 35$ & $108 / 51$ & $114 / 19$ \\
\hline & 800 & $116 / 39$ & $119 / 38$ & $128 / 61$ & $134 / 99$ \\
\hline & 1200 & $132 / 20$ & $135 / 51$ & $145 / 70$ & $152 / 74$ \\
\hline & 1600 & $146 / 04$ & $149 / 64$ & $160 / 70$ & $168 / 34$ \\
\hline \multirow{4}{*}{$\begin{array}{l}\text { Helvaci } \\
\text { and Khan }\end{array}$} & 400 & $96 / 21$ & $98 / 55$ & $106 / 68$ & $112 / 46$ \\
\hline & 800 & $114 / 45$ & $117 / 42$ & $126 / 48$ & $133 / 05$ \\
\hline & 1200 & $129 / 41$ & $133 / 01$ & $143 / 01$ & $150 / 04$ \\
\hline & 1600 & $142 / 34$ & $145 / 94$ & $157 / 19$ & $164 / 84$ \\
\hline \multirow{4}{*}{$\begin{array}{c}\% \\
\text { Difference }\end{array}$} & 400 & $1 / 53$ & $1 / 79$ & $1 / 69$ & $1 / 52$ \\
\hline & 800 & $1 / 67$ & $1 / 64$ & $1 / 65$ & $1 / 44$ \\
\hline & 1200 & $2 / 10$ & $1 / 85$ & $1 / 85$ & $1 / 77$ \\
\hline & 1600 & $2 / 53$ & $2 / 48$ & $2 / 19$ & $2 / 08$ \\
\hline
\end{tabular}

In addition, numerical results of present study are compared to the experimental results of Helvacy and Khan in Table 4.

Table 4 Comparing average heat transfer coefficient for numerical and experimental results of of Helvacy and Khan[33]

\begin{tabular}{|c|c|r|c|}
\hline \multicolumn{4}{|c|}{ Comparing average heat transfer coefficient results } \\
\hline \multicolumn{3}{|c|}{$\mathrm{D}=4.75 \mathrm{~m}$ L=1.2mm;Wall heat flux $=1000 \mathrm{w} / \mathrm{m} 2$} \\
\hline $\mathrm{x}$ & $\begin{array}{c}\text { Present } \\
\text { study }\end{array}$ & $\begin{array}{c}\text { Experimental } \\
\text { Results }\end{array}$ & $\%$ Difference \\
\hline $0 / 3$ & $1099 / 2$ & $1004 / 37$ & $9 / 44$ \\
\hline $0 / 5$ & $967 / 8$ & $856 / 25$ & $13 / 03$ \\
\hline $0 / 7$ & $912 / 6$ & $778 / 13$ & $17 / 28$ \\
\hline $0 / 95$ & $743 / 3$ & $720 / 03$ & $3 / 23$ \\
\hline $1 / 17$ & $694 / 9$ & $687 / 24$ & $1 / 12$ \\
\hline
\end{tabular}




\section{RESULTS AND DISCUSSION}

Figure 5 illustrates the variations of pressure drop with respect to slip length in different dosage of $\mathrm{Al}_{2} \mathrm{O}_{3}$ and $\mathrm{SiO}_{2}$. Using walls with slip boundary condition decreases the pressure drop while adding nanoparticles to the base fluid tend to increase it. Considering the case when the flow is fully developed, typically $\operatorname{Re}=800$, it is worthwhile to investigate the effect of doping different concentrations of $\mathrm{Al}_{2} \mathrm{O}_{3}$ and $\mathrm{SiO}_{2}$.

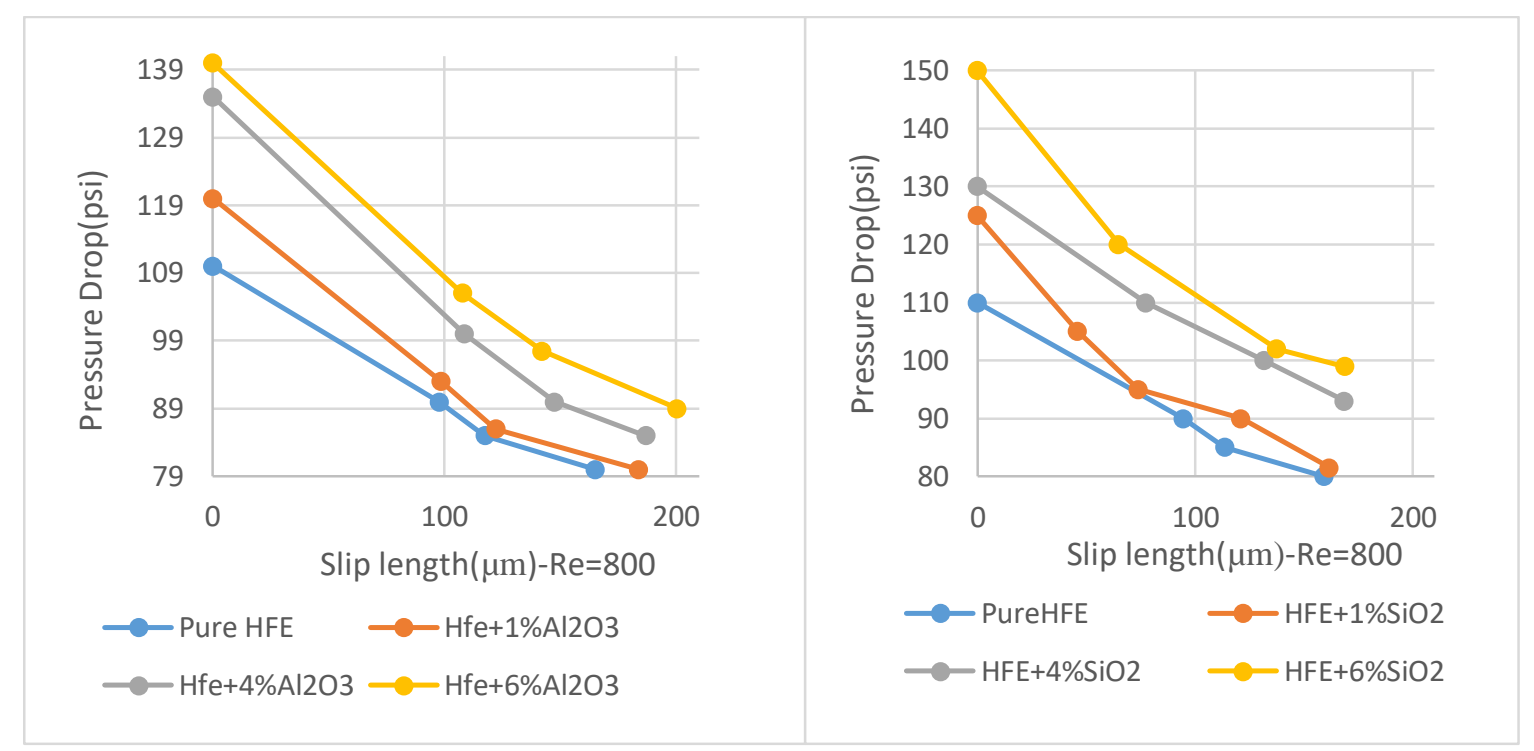

Figure 5. Pressure drop for different slip lengths $-\mathrm{Re}=800$

The pressure drop depends on the friction and magnitude of velocity gradient near the wall. Using of slipping surfaces tend to decrease the friction whereby the pressure drop decreases. Results for pressure drop with slip length of $100 \mu \mathrm{m}$ shows $20 \%$ decrease in comparison to noslip wall. Comparing the results for two different nanoparticles, $\mathrm{Al}_{2} \mathrm{O}_{3}$ and $\mathrm{SiO}_{2}$ shows that pressure drop in HFE7000 fluid with dispersed nanoparticles of $\mathrm{SiO}_{2}$ is more significant than the $\mathrm{Al}_{2} \mathrm{O}_{3}$ nanofluids. For example, pressure drop for HFE7000 fluid with $1 \%$ volume concentration of $\mathrm{SiO}_{2}$ is 106 psi while it is 103 psi for the $\mathrm{Al}_{2} \mathrm{O}_{3}$ nanofluid. Figure 6 shows that the fluid flow illustrates velocity values adjacent to the wall since a slip condition is exerted at the wall. 


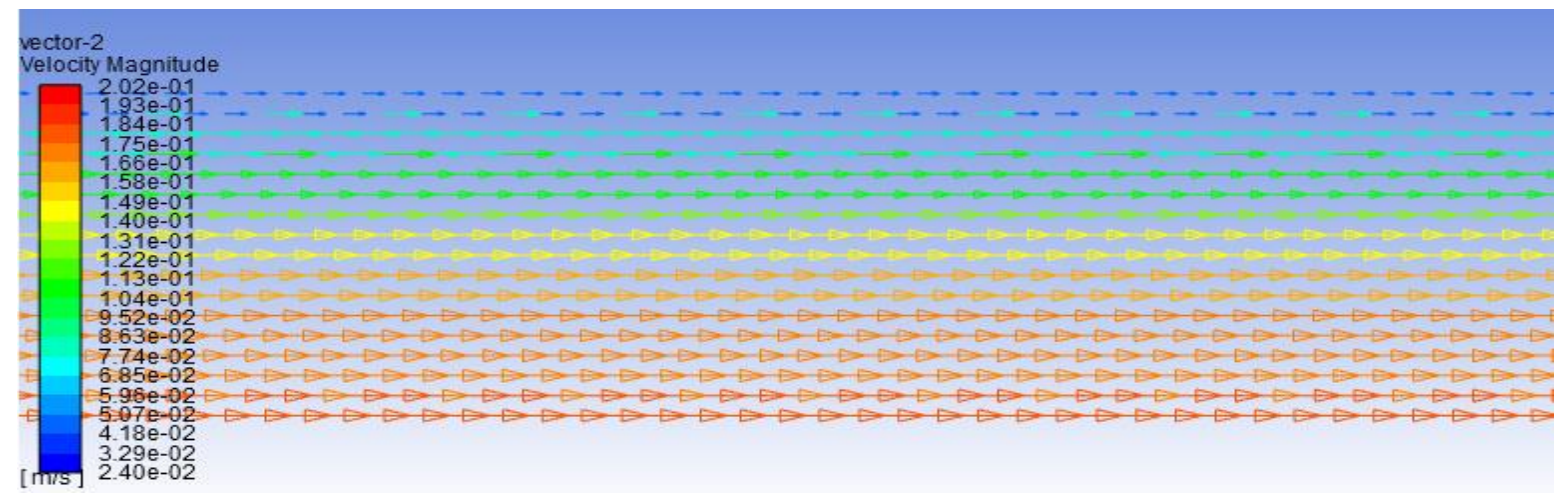

Figure 6 Velocity magnitude of fluid

The analysis of the flow field in a boundary layer adjacent to the wall shows the occurrence of the velocity slip at the wall. This slip also is indicated in the previous studies investigated by Yazdi et al [34]. Figure 7 illustrates the combination effects of velocity gradient and slip condition for various values of volume concentration of $\mathrm{Al}_{2} \mathrm{O}_{3}$ and $\mathrm{SiO}_{2}$ dispersed in HFE7000 at Reynolds number of 800 . Velocity gradient increases with the enhancement of Reynolds number and enhancement in volume concentration of nanofluids. Results indicate that the velocity gradient for nanofluids with $6 \%$ volume concentration of $\mathrm{Al}_{2} \mathrm{O}_{3}$ is about $20 \%$ more than using of pure base fluid in similar condition. Comparing the results of two different nanoparticles shows larger velocity gradient for $\mathrm{Al}_{2} \mathrm{O}_{3}$ nanofluids.

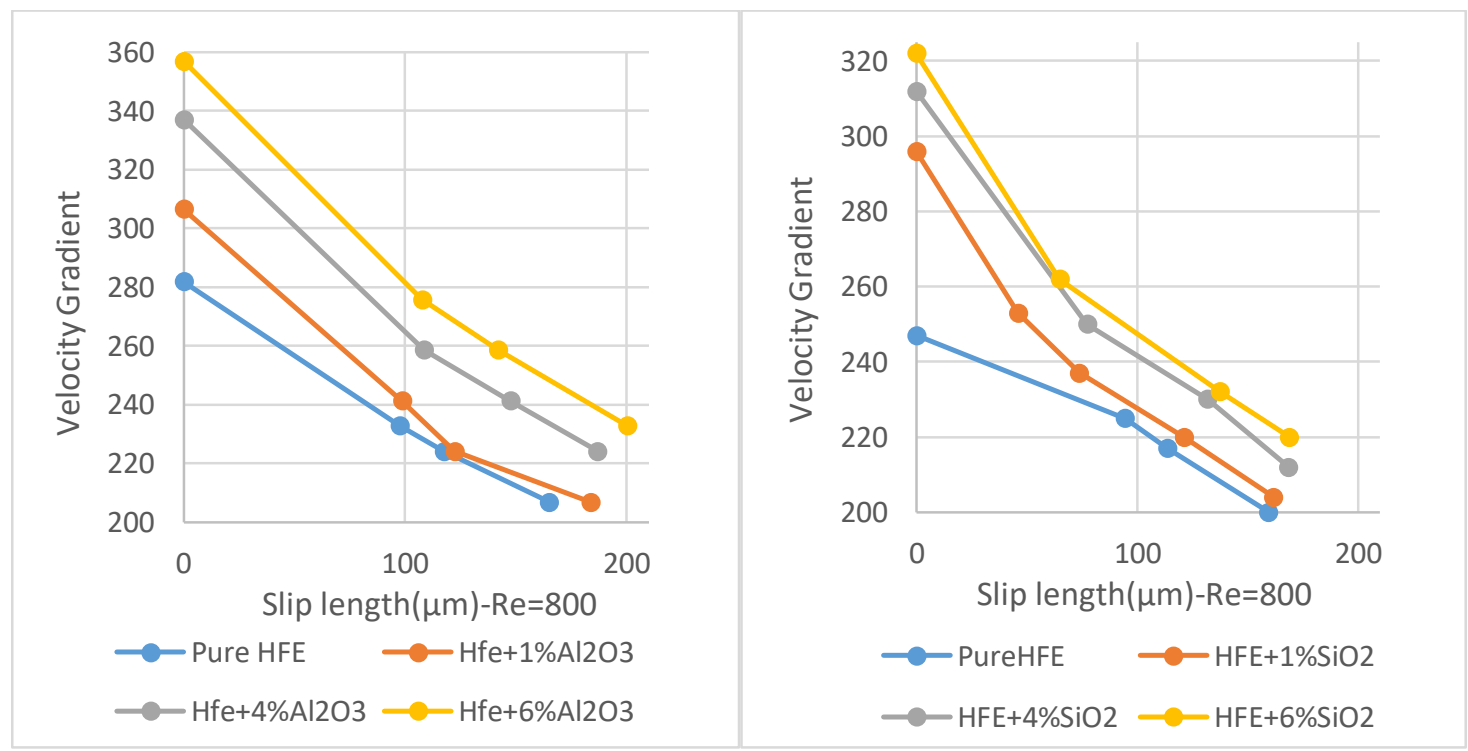

Figure 7 Velocity gradient for different slip lengths $-\mathrm{Re}=800$

Increasing the inlet velocity makes velocity gradient to increase. Slip velocity is $11,24,36$, and $48 \mathrm{~mm} / \mathrm{s}$ for different Reynolds number of 400, 800, 1200, and1600 respectively. These 
velocities are on average about $22.5 \%$ of the free flow velocity. Slip velocity for different Reynolds number at various slip lengths is shown in Figure.8

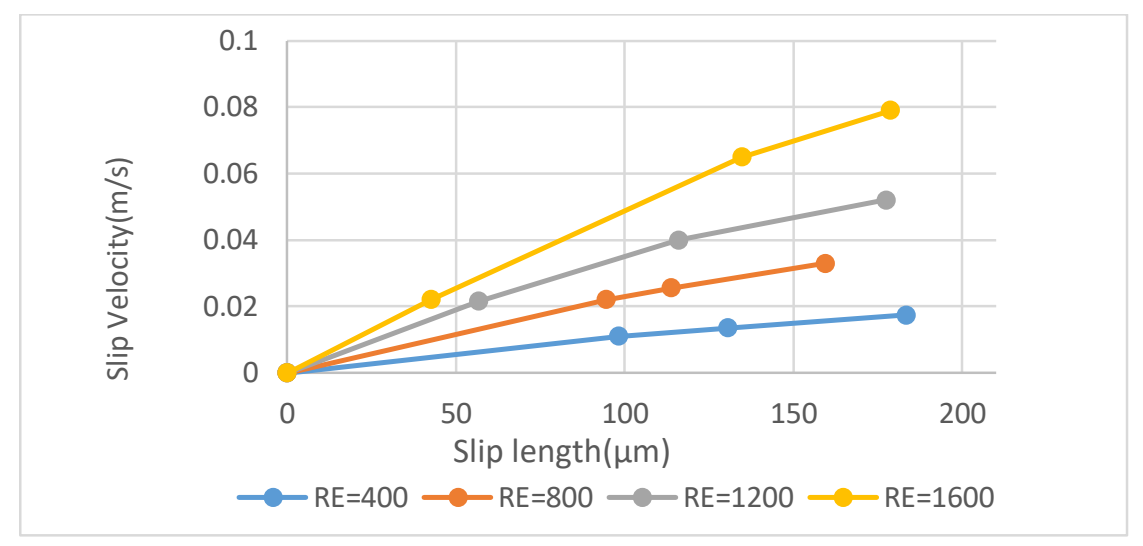

Figure 8 Slip velocity for different slip lengths $-\mathrm{Re}=800$

Skin friction coefficient for different volume concentration of $\mathrm{Al}_{2} \mathrm{O}_{3}$ and $\mathrm{SiO}_{2}$ is indicated in Figure 9. The results show mean skin friction coefficient increases with enhancement of nanoparticles volume concentration. This coefficient decreases while there is slip at the wall and enhances with increase in Reynolds number. It is worth pointing out that $\mathrm{HFE}-\mathrm{SiO}_{2}$ shows higher values of shear stress compared with the $\mathrm{HFE}-\mathrm{Al}_{2} \mathrm{O}_{3}$. Figure 10 also shows an example of problem solution results for skin friction coefficient $\left(\mathrm{C}_{\mathrm{f}}\right)$.
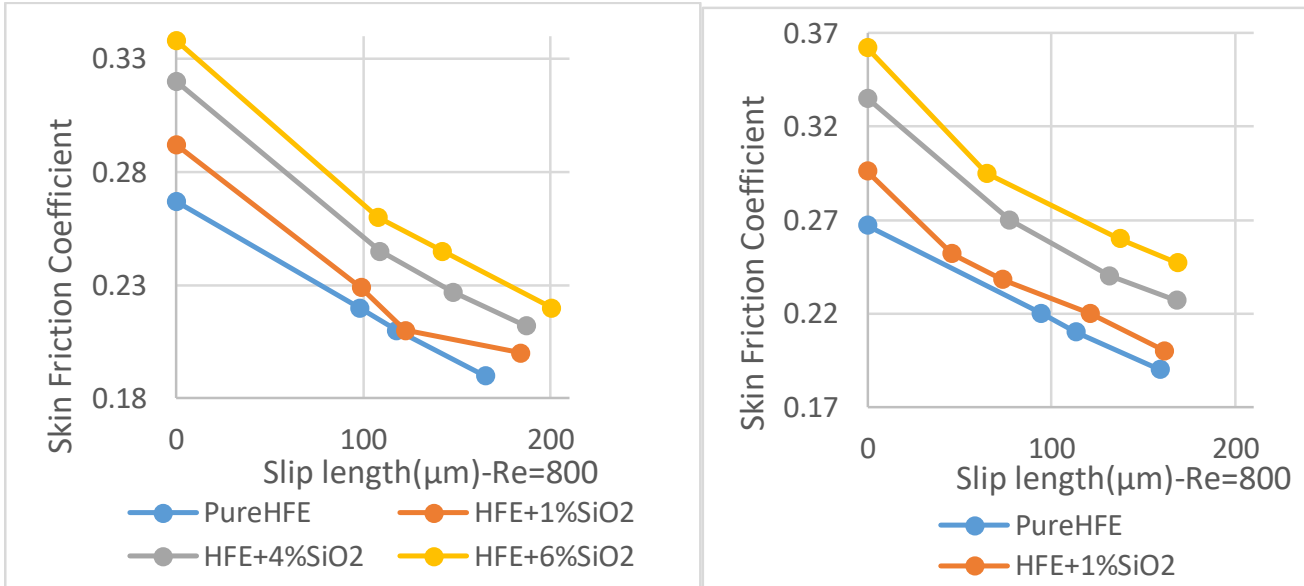

Figure 9 Skin friction coefficient for different slip lengths $-\mathrm{Re}=800$ 


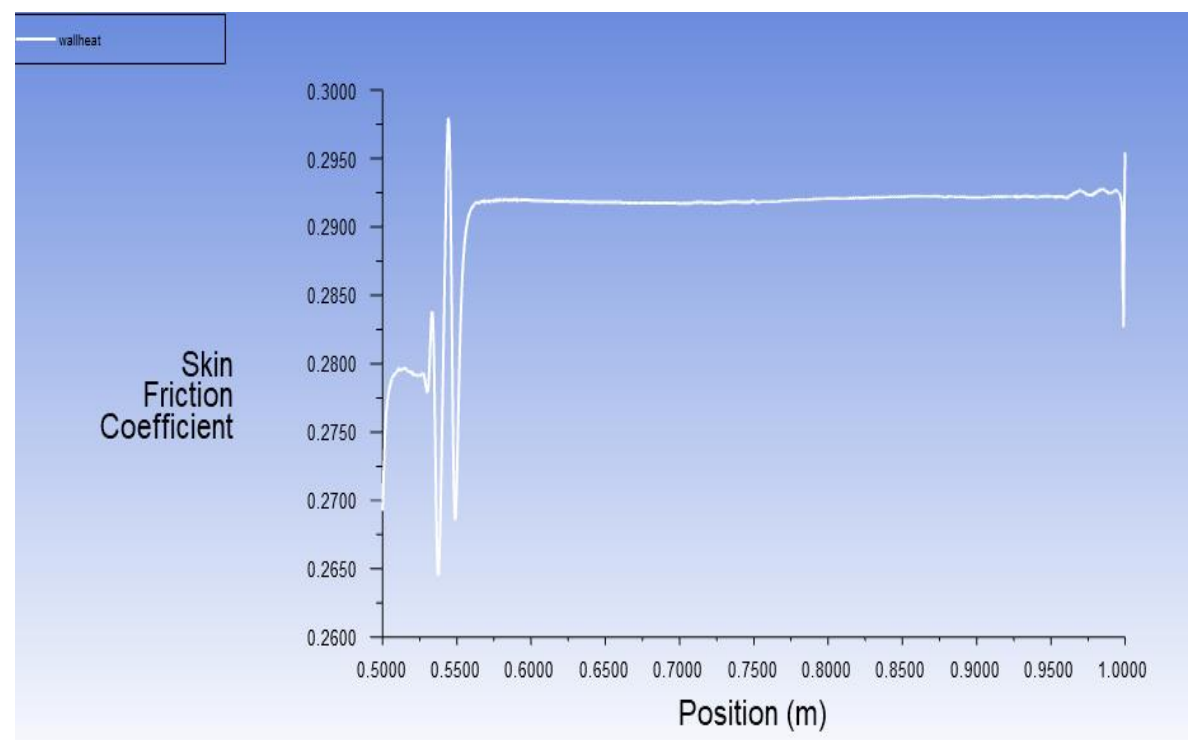

Figure 10 Skin friction coefficient

Velocity slip condition at the wall and adding nanoparticles tend to decease the result of $T_{w}$ $\mathrm{T}_{\mathrm{fm}}$ and this is due to the heat transfer coefficient increases in both of them. Figure 11 indicates $h_{\text {ave }}$ for different volume concentration of $\mathrm{Al}_{2} \mathrm{O}_{3}$ and $\mathrm{SiO}_{2}$ dispersed in pure $\mathrm{HFE}$ at different slip lengths. It is noted that $\mathrm{h}_{\text {ave }}$ at the $100 \mu \mathrm{m}$ slip length is about $14 \%$ more than nonslip boundary

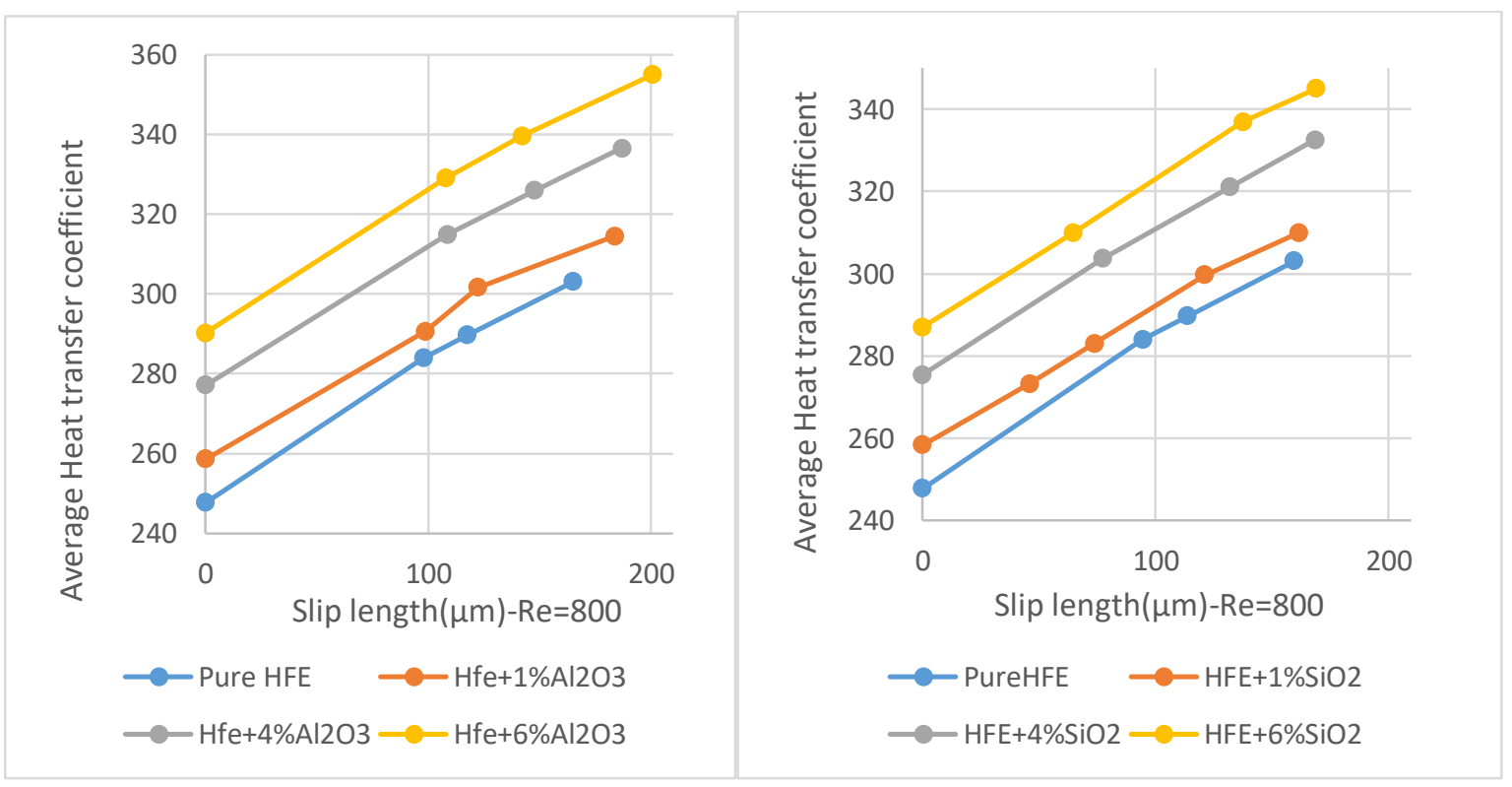

Figure 11 Average heat transfer coefficient $-\mathrm{Re}=800$

Figure 12 illustrates the $h_{\text {ave }}$ versus slip lengths for various values of Reynolds numbers. Increasing the Reynolds number in laminar flow changes $h_{\text {ave }}$ versus slip length graphs from 
linear to parabolic shape and the consequence indicates that the increasing of slip length has less influence on $\mathrm{h}_{\text {ave }}$ with low Reynolds numbers.

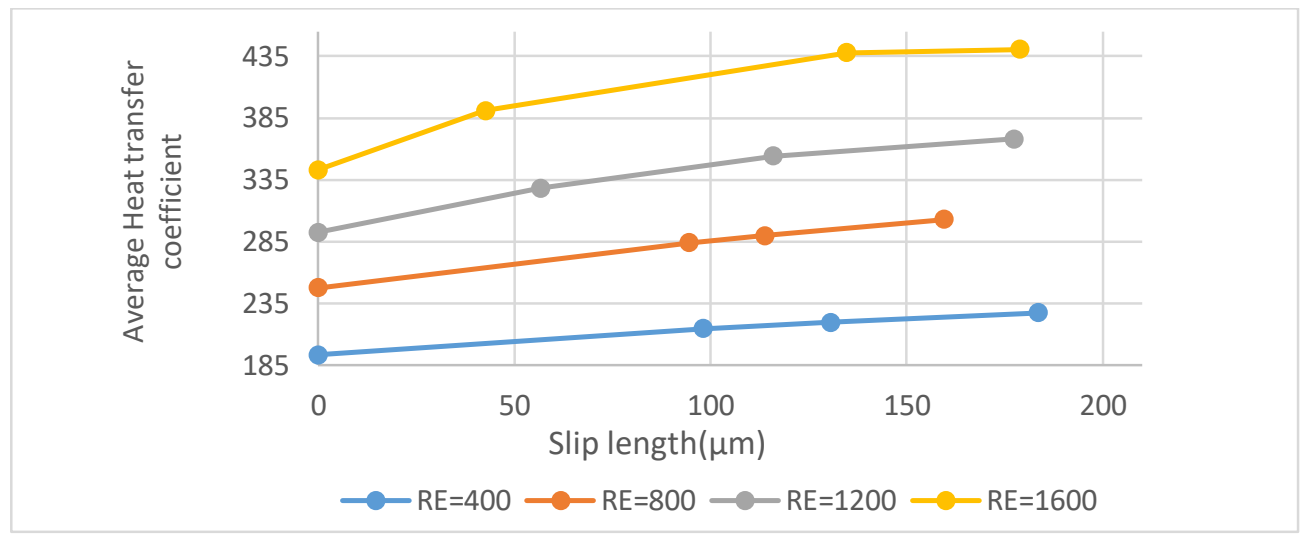

Figure 12 Average heat transfer coefficient for different Reynolds numbers

Figure 13 shows friction irreversibility versus slip lengths for various values of nanofluid concentrations. It is noted that the slip condition at the wall decreases the friction factor and as a results it reduces the friction irreversibility. Adding nanoparticles also tend to increase the friction irreversibility.
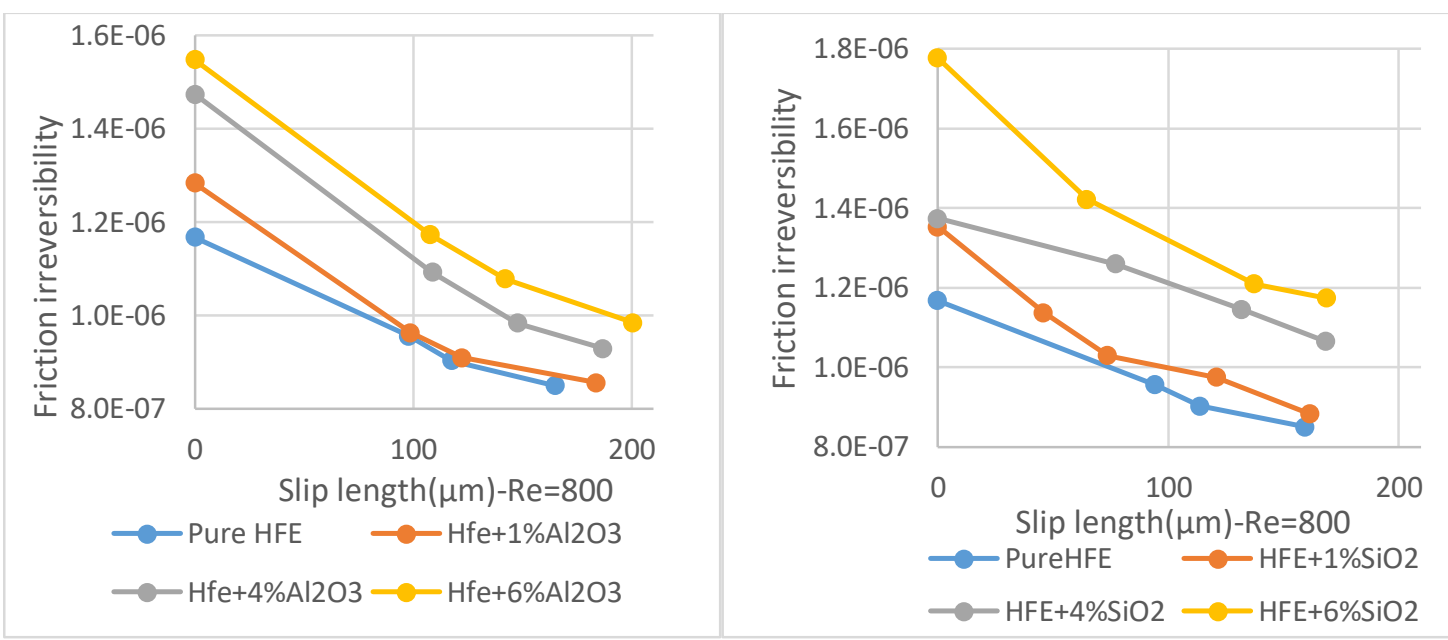

Figure 13 friction irreversibility versus slip lengths

Figure 14 shows thermal irreversibility versus slip lengths for various values of nanofluid volume concentrations. According to equation (13), thermal irreversibility has shown an inverse relation with the Nusselt number and therefore an increase of $\mathrm{h}_{\text {ave }}$ tend to reduce the thermal irreversibility. 


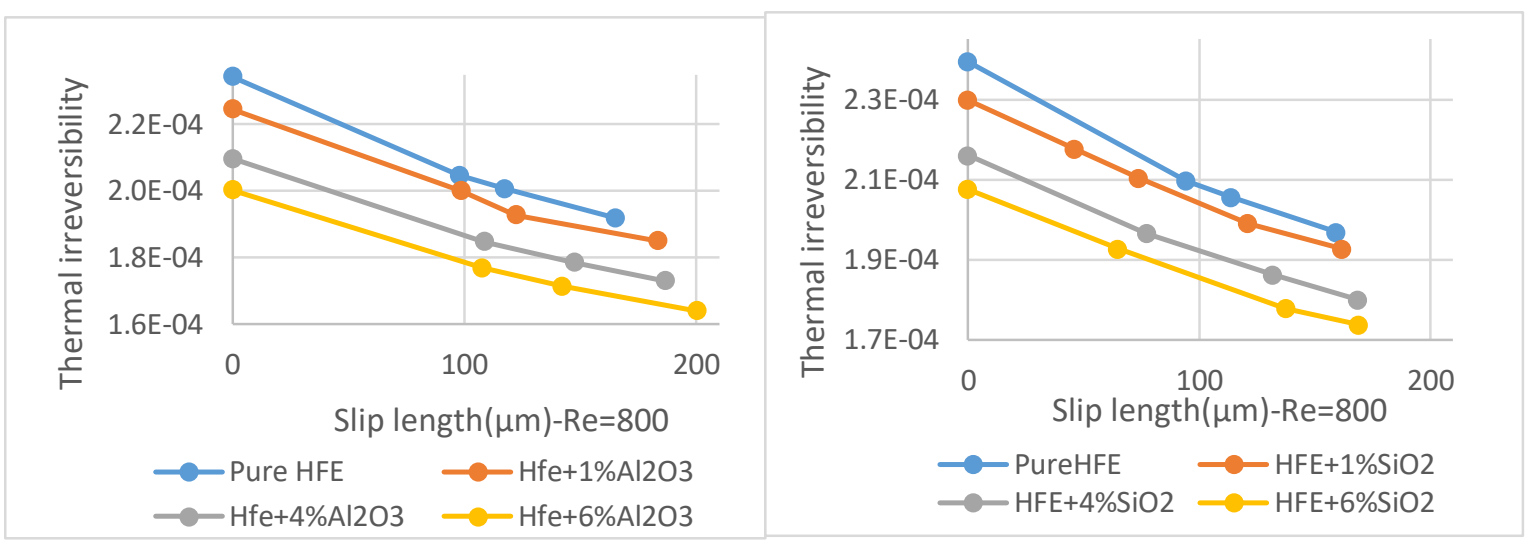

Figure 14 Thermal irreversibility versus slip lengths

Total entropy generation consists of two parts, friction and thermal irreversibility. Figure 15 illustrates the total entropy generation versus slip lengths for various values of nanofluid volume concentrations. It is interesting to note that the total entropy generation will decrease by both the nanofluid volume concentration and slip lengths. It means using HFE7000 nanofluids accompanied by superhydrophobic heat exchanger walls could decrease the total entropy generation leading to a reduction in exergy losses. The total entropy generation for HFE7000 with $6 \%$ volume concentration of $\mathrm{Al}_{2} \mathrm{O}_{3}$ with slip length of $100 \mu \mathrm{m}$ is almost $25 \%$ less than the case using pure base fluid without slip boundary condition.

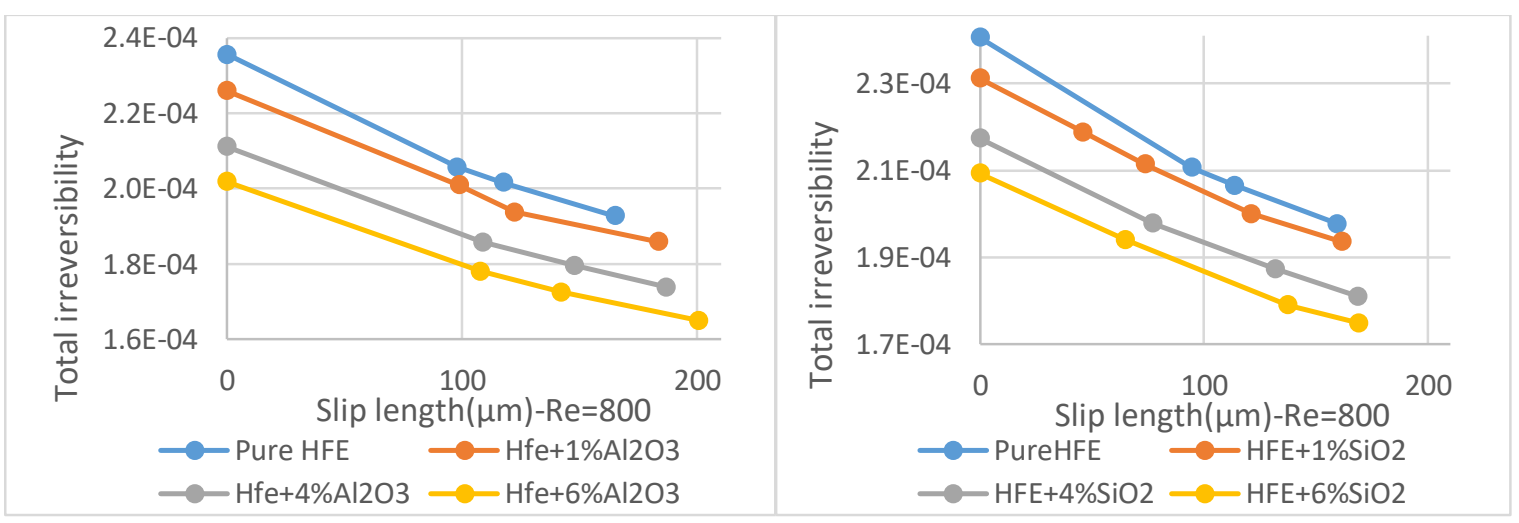

Figure 15 Total irreversibility versus slip lengths

The effect of involved parameters on Bejan number shown in Figure 16. The results show that Bejan number decreases with adding nanoparticles to the base fluid due to the decreasing of thermal irreversibility in total entropy generation. Results are different for $\mathrm{Al}_{2} \mathrm{O}_{3}$ and $\mathrm{SiO}_{2}$ because of their difference in pressure drop and consequently frictional irreversibility. Pressure drop is slightly larger for nanofluids that contain $\mathrm{SiO}_{2}$ nanoparticles. The friction 
irreversibility is larger for $\mathrm{SiO}_{2}$ nanofluid whereby the Bejan Number value is smaller compared with the case of $\mathrm{AL}_{2} \mathrm{O}_{3}$.
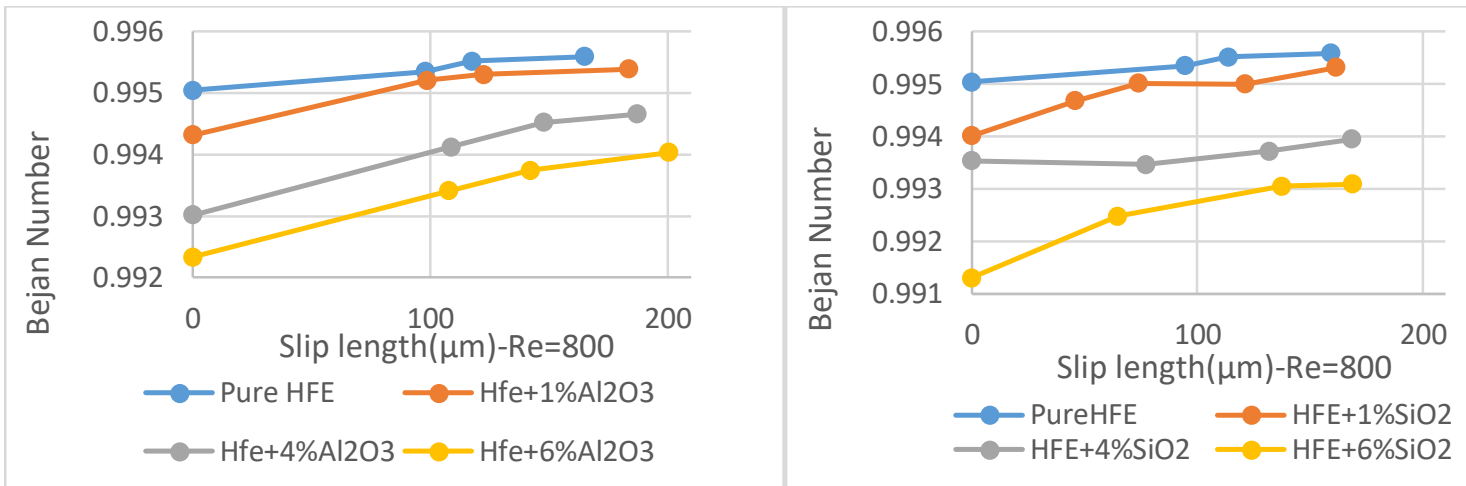

Figure 16 Bejan number versus slip length

Figure 17 shows total heat transfer rate versus slip lengths for different Reynolds numbers. The total heat transfer rate decreases with applying the slip to the wall and increases with the Reynolds number for the slip lengths smaller than $100 \mu \mathrm{m}$.

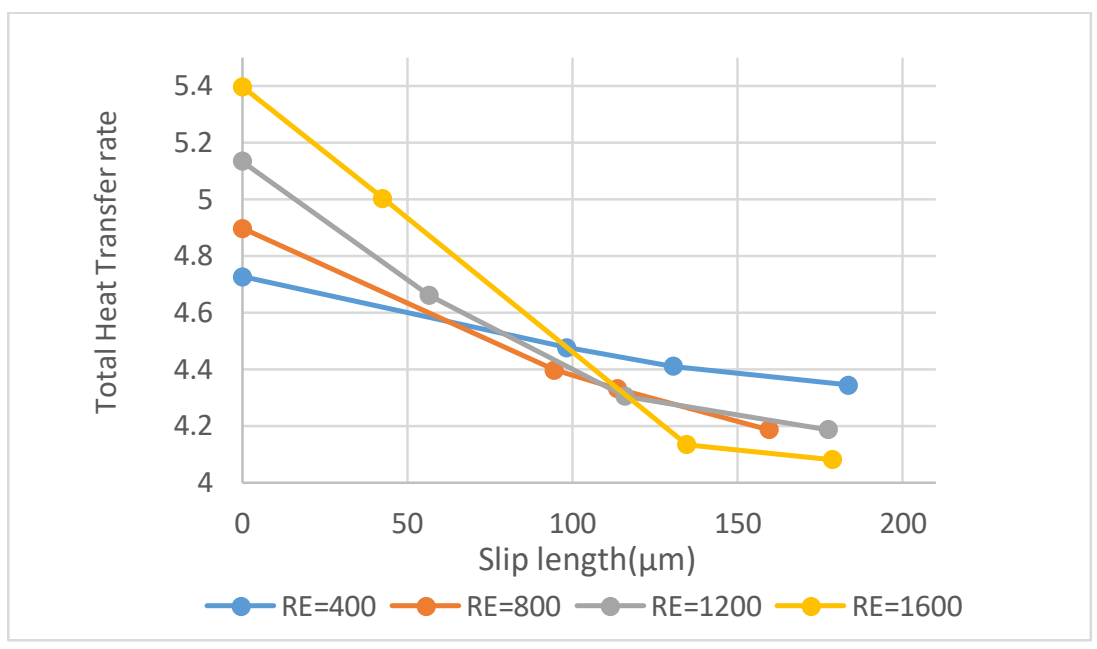

Figure 17 Total heat transfer rate versus slip length

Results show for the slip lengths larger than $100 \mu \mathrm{m}$, Reynolds numbers show opposite effects on total heat transfer rate. This means that if we intend to increase the total heat transfer rate by Reynolds number, we should predict our optimum slip lengths results to reach the highest heat transfer rate. At slip length of about $100 \mu \mathrm{m}$ the effect of Reynolds number on total heat transfer will be neglectable. This is due to the slip condition effect at the wall whereby the friction drops and the flow cannot touch the wall properly leading a decrease of total heat transfer rate. 


\section{CONCLUSION}

In most heat exchanger applications, the pressure drop reduction and heat transfer enhancement will be desired. In this study heat transfer and entropy generation analysis of a single phase homogeneous nanorefrigerant flow is analyzed with a constant wall heat flux in the presence of slip boundary condition. Using of partial slip at the wall tends to decreases total heat transfer rate but illustrates positive effect on the decreasing pressure drop leading lower entropy generation at the wall. Based on the results and discussions, the following conclusions can be reached:

By using of slip condition walls, mean pressure drop reduces about $25 \%$ on average.

Adding nanoparticles to the fluid enhances heat transfer coefficient about $17 \%$.

Total entropy generation while using of nanoparticles and slip wall condition decreases about $20 \%$ in comparison to pure HFE7000 flowing in a no-slip pipe

Slip length decreases the total heat transfer rate. At slip length of $100 \mu \mathrm{m}$, total heat transfer rates are equal for different inlet velocity of fluidand it means the effect of Reynolds number would be negligible.

Friction irreversibility increases as the inlet velocity enhances and this means at larger Reynolds numbers the order of friction and thermal irreversibility can get closer and in such problems finding an optimum Reynolds number can be useful.

The total entropy generation will decrease by both the nanofluid volume concentration and slip lengths 


\section{References}

1. Sarma, R., Nath, Ashim Jyoti, Konwar, Tonmoy, Mondal, Pranab Kumar, Wongwises, and Somchai, Thermo-hydrodynamics of a viscoelastic fluid under asymmetrical heating. International Journal of Heat and Mass Transfer, 2018. 125: p. 515-524.

2. Al-Shamani, A.N., Yazdi, Mohammad H., Alghoul, M. A., Abed, Azher M., Ruslan, M. H. Mat, Sohif, and Sopian, K., Nanofluids for improved efficiency in cooling solar collectors - A review. Renewable and Sustainable Energy Reviews, 2014. 38: p. 348-367.

3. Mondal, P.K. and S. Dholey, Effect of conjugate heat transfer on the irreversibility generation rate in a combined Couette-Poiseuille flow between asymmetrically heated parallel plates: The entropy minimization analysis. Energy, 2015. 83(C): p. 55-64.

4. Helvaci, H.U. and Z.A. Khan, Experimental study of thermodynamic assessment of a small scale solar thermal system. Energy Conversion and Management, 2016. 117: p. 567-576.

5. Gaikwad, H.S., Roy, Apurba, Mondal, Pranab Kumar, Chimres, Nares, Wongwises, and Somchai, Irreversibility analysis in a slip aided electroosmotic flow through an asymmetrically heated microchannel: The effects of joule heating and the conjugate heat transfer. Analytica Chimica Acta, 2019. 1045: p. 85-97.

6. Moghaddami, M., S. Shahidi, and M. Siavashi, Entropy Generation Analysis of Nanofluid Flow in Turbulent and Laminar Regimes. Journal of Computational and Theoretical Nanoscience, vol. 9, issue 10, pp. 1586-1595, 2012. 9: p. 1586-1595.

7. Singh, P.K., Anoop, K. B., Sundararajan, T., and Das, Sarit K., Entropy generation due to flow and heat transfer in nanofluids. International Journal of Heat and Mass Transfer, 2010. 53(21): p. 4757-4767.

8. Shalchi-Tabrizi, A. and H.R. Seyf, Analysis of entropy generation and convective heat transfer of A/2O3 nanofluid flow in a tangential micro heat sink. International Journal of Heat and Mass Transfer, 2012. 55(15): p. 4366-4375.

9. Gaikwad, H.S., P.K. Mondal, and S. Wongwises, Non-linear drag induced entropy generation analysis in a microporous channel: The effect of conjugate heat transfer. International Journal of Heat and Mass Transfer, 2017. 108: p. 2217-2228.

10. Daniello, R., N. Waterhouse, and J. Rothstein, Drag reduction in turbulent flows over superhydrophobic surfaces. Physics of Fluids, 2009. 21.

11. $\mathrm{Xu}, \mathrm{H} .$, Manufacture, characterisation and novel investigations of superhydrophobic surfaces. 2017, University of Liverpool.

12. Yazdi, M.H., Abdullah, Shahrum, Hashim, Ishak, Zaharim, Azami, Sopian, and Kamaruzzaman, Entropy generation analysis of the MHD flow over nonlinear permeable stretching sheet with partial slip. 6th IASME / WSEAS International Conference on Energy and Environment, 2013.

13. Sobamowo, M.G., L.O. Jayesimi, and M.A. Waheed, Magnetohydrodynamic squeezing flow analysis of nanofluid under the effect of slip boundary conditions using variation of parameter method. Karbala International Journal of Modern Science, 2018. 4(1): p. 107-118.

14. Yazdi, M.H., Abdullah, S., Hashim, I., and Sopian, K., Slip MHD liquid flow and heat transfer over non-linear permeable stretching surface with chemical reaction. International Journal of Heat and Mass Transfer, 2011. 54(15): p. 3214-3225.

15. Somasekhar, K., Malleswara Rao, K. N. D., Sankararao, V., Mohammed, Raffi,Veerendra, M. and Venkateswararao, T., A CFD Investigation of Heat Transfer Enhancement of Shell and Tube Heat Exchanger Using Al2o3-Water Nanofluid. Materials Today: Proceedings, 2018. 5(1, Part 1): p. 1057-1062.

16. Malvandi, A. and D.D. Ganji, Brownian motion and thermophoresis effects on slip flow of alumina/water nanofluid inside a circular microchannel in the presence of a magnetic field. International Journal of Thermal Sciences, 2014. 84: p. 196-206.

17. Chen, H., X. Fu, and Q. Liu, Modelling slip flow in micro/nano gaps with moving boundary. Microelectronic Engineering, 2014. 123: p. 167-170. 
18. Xie, Z.-I., N. Ta, and Z.-s. Rao, The lubrication performance of water lubricated bearing with consideration of wall slip and inertial force. Journal of Hydrodynamics, Ser. B, 2017. 29(1): p. 52-60.

19. Rahmati, A.R., Akbari, Omid Ali, Marzban, Ali, Toghraie, Davood, Karimi, Reza, Pourfattah, and Farza, Simultaneous investigations the effects of non-Newtonian nanofluid flow in different volume fractions of solid nanoparticles with slip and no-slip boundary conditions. Thermal Science and Engineering Progress, 2018. 5: p. 263-277.

20. Xie, F., Li, Yanzhong, Wang, Xingbao, Wang, Ying, Lei, Gang, and Xing, Kewei, Numerical study on flow and heat transfer characteristics of low pressure gas in slip flow regime. International Journal of Thermal Sciences, 2018. 124: p. 131-145.

21. Mehrdad Karimzadehkhouei, Mostafa Shojaeian, Abdolali Khalili Sadaghiani, Kür, sat, Sendur, M. Pinar Mengüç and Ali Kosar, Entropy Generation Analysis of Laminar Flows of Water-Based Nanofluids in Horizontal Minitubes under Constant Heat Flux Conditions. Entropy, 2018. 20(4).

22. Davarnejad, R. and M. Jamshidzadeh, CFD modeling of heat transfer performance of MgOwater nanofluid under turbulent flow. Engineering Science and Technology, an International Journal, 2015. 18(4): p. 536-542.

23. Lemmon, E., M. Huber, and M. McLinden, NIST Standard Reference Database 23, Reference Fluid Thermodynamic and Transport Properties (REFPROP), version 9.0, National Institute of Standards and Technology. R1234yf. fld file dated December, 2010. 22: p. 2010.

24. Pathipakka, G. and P. Sivashanmugam, Heat transfer behaviour of nanofluids in a uniformly heated circular tube fitted with helical inserts in laminar flow. Superlattices and Microstructures, 2010. 47(2): p. 349-360.

25. Salman, B.H., H.A. Mohammed, and A.S. Kherbeet, Numerical and experimental investigation of heat transfer enhancement in a microtube using nanofluids. International Communications in Heat and Mass Transfer, 2014. 59: p. 88-100.

26. Pak, B.C. and Y.I. Cho, Hydrodynamic and Heat Transfer Study of Dispersed Fluids With Submicron Metallic Oxide Particle. Experimental Heat Transfer, 1998. 11(2): p. 151-170.

27. Pak, B. and Y. Cho, Hydrodynamic and Heat Transfer Study of Dispersed Fluids With Submicron Metallic Oxide Particle. Experimental Heat Transfer, 1998. 11: p. 151-170.

28. Einstein, A., Eine neue Bestimmung der Moleküldimensionen. Annalen der Physik, 1906. 324(2): p. 289-306.

29. Hamilton, R.L. and O.K. Crosser, Thermal Conductivity of Heterogeneous Two-Component Systems. Industrial \& Engineering Chemistry Fundamentals, 1962. 1(3): p. 187-191.

30. Mahian, O., Kianifar, Ali, Kleinstreuer, Clement, Al-Nimr, Moh'd A., Pop, Ioan, Sahin, Ahmet Z., Wongwises, and Somcha, A review of entropy generation in nanofluid flow. International Journal of Heat and Mass Transfer, 2013. 65: p. 514-532.

31. Yazdi, M.H., Abdullah, Shahrir, Hashim, Ishak, Sopian, and Kamaruzzaman, Effects of Viscous Dissipation on the Slip MHD Flow and Heat Transfer past a Permeable Surface with Convective Boundary Conditions. Energies, 2011. 4(12).

32. Saha, G. and M.C. Paul, Heat transfer and entropy generation of turbulent forced convection flow of nanofluids in a heated pipe. International Communications in Heat and Mass Transfer, 2015. 61: p. 26-36.

33. Helvaci, H.U. and Z.A. Khan, Heat transfer and entropy generation analysis of HFE 7000 based nanorefrigerants. International Journal of Heat and Mass Transfer, 2017. 104: p. 318-327.

34. Yazdi, M.H., Abdullah, Shahrir, Hashim, Ishak, Sopian, and Kamaruzz, Reducing Entropy Generation in MHD Fluid Flow over Open Parallel Microchannels Embedded in a Micropatterned Permeable Surface. Entropy, 2013. 15(11). 